\title{
Emergência de uma nova cartografia \\ global das mídias e das culturas \\ Emergence of a new global cartography of media and cultures
}

\section{Paula Roberta Santana Rocha}

Jornalista; Mestranda em Comunicação pelo Programa de Pós-graduação em Comunicação da Universidade Federal de Goiás; Bolsista da FAPEG - Fundação de Amparo à Pesquisa do Estado de Goiás - Goiás (GO), Brasil. E-mail: paula_roberta_1990@hotmail.com

Lançado em 2012, o livro do jornalista, professor (doutor em Sociologia) e pesquisador francês Frédéric Martel, Mainstream ${ }^{1}$ representa um trabalho inovador e ambicioso no que concerne à busca pela compreensão da atual cartografia das mídias e das culturas, pós-revolução digital. Dotado de uma linguagem simples e acessível, construída por meio de um estilo narrativo semelhante à reportagem, só que em primeira pessoa, a obra contempla uma investigação sólida e cuidadosa. Não é um livro que apresenta teorias nem possui vigor academicista (apesar de o autor ser acadêmico), mas, sim, uma pesquisa de campo, na qual Martel utiliza como fonte quase que exclusivamente as entrevistas que realizou nos mais de 30 países que visitou. Para conseguir chegar a algumas das respostas pretendidas, o autor viajou para os quatro cantos do mundo, entrevistando mais de 1.250 pessoas que fazem parte da indústria das mídias e do entretenimento². Os países que visitou para realizar a pesquisa foram: Arábia Saudita, Argentina, Bélgica, Brasil, Camarões, Canadá, China, Cingapura, Coreia do Sul, Dinamarca, Egito, Emirados Árabes Unidos (Dubai), Espanha, Estados Unidos, Índia, Indonésia, Israel, Itália, Japão, Líbano, México, Palestina, Catar, República Tcheca, Reino Unido, Síria, Tailândia, Turquia, Venezuela e Vietnã.

Em primeiro lugar, fica claro que o estudo se concentra na geopolítica das indústrias do entretenimento (como cinema, música, novelas), deixando para outros planos o universo da informação, que na maioria dos casos, porém, está intrinsecamente ligado a essas indústrias. Diferentemente do termo "indústria cultural," Martel utiliza na maior parte do tempo o termo "indústrias criativas", justificando certo desgaste conceitual daquela concepção emanada da Escola de Frankfurt. Isso se dá porque o significado do termo, desde sua criação

1 MARTEL, Frédéric. Mainstream. A guerra global das mídias e das culturas. Tradução: Clóvis Marques. Rio de Janeiro: Civilização Brasileira, 2012. 490 p.

2 Para informações complementares, além do livro, o autor disponibiliza o site fredericmartel.com, em que é possível encontrar complementos, como a lista de todos os entrevistados, bibliografia, glossário etc. pelos teóricos frankfurtianos, tenta separar aquilo que é a genuína arte (representante da alta cultura, a que as classes menos abastadas não podem ter acesso, já que não tem educação adequada para isso) das produções culturais em massa, ou "cultura de mercado", construídas com o objetivo de propiciar o lazer e a alienação das massas.

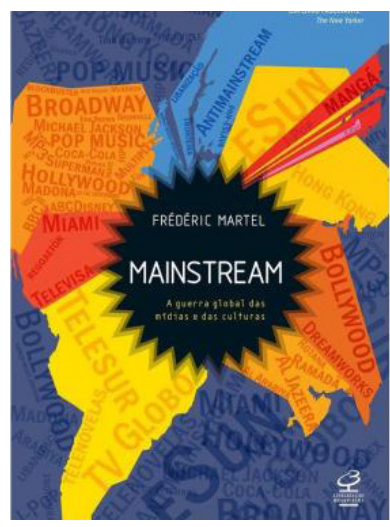
Tais produções culturais, portanto, cumpririam a função de promover lazer para o divertimento, direcionado a um público de massa, menos educado.

O termo "indústrias criativas", além de cumprir a função de eufemismo, soando assim menos ofensivo, envolve uma multiplicidade de produções e serviços culturais voltados para o mercado. Ressalte-se que isso não significa que essas indústrias também não produzam arte - a obra não se detém dessas questões profundamente, pois esse não é o seu real objetivo. Nas palavras do autor:

[...] vou falar aqui de "indústrias criativas" ou "indústrias de conteúdos", expressões que incluem os meios de comunicação e o universo digital, e às quais dou preferência sobre "indústrias culturais", forma por demais conotada, datada e hoje já imperfeita. Pois já não se trata simplesmente de produtos culturais, mas também de serviços. Não só de cultura, mas também de conteúdos e formatos. Não só de indústrias, mas também de governos em busca de soft power e de microempresas atrás de inovações nas mídias e na criação desmaterializadas (MARTEL, 2012, p. 15).

Dessa forma, o interesse pela geopolítica dessas indústrias engloba todo um modelo econômico de criação de conteúdos, o diálogo entre os conteúdos e as redes que os produzem ou financiam, "o business do show business". Assim, o modelo de funcionamento desse novo capitalismo cultural, faz emergir, em todo o mundo, uma nova cartografia de mídias e culturas. 


\section{Emergência de uma nova cartografia global das mídias e das culturas}

Antes de iniciar uma explanação acerca da estrutura do livro, é interessante atentar para seu título Mainstream, igual em todas as edições estrangeiras, e o subtítulo brasileiro A guerra global das mídias e das culturas. Mainstream, um termo já conhecido no mundo acadêmico por meio das teorias do imperialismo cultural, trata-se de uma palavra de origem americana, que designa aquilo destinado ao grande público, o que é dominante, popular. Ao mesmo tempo, pode ter tanto um sentido positivo, quando se trata de cultura (cultura mainstream, destinada a todos), como um sentido negativo, quando se trata de cultura hegemônica, dominante, que coloca as outras culturas em estado de assujeitamento. É a partir da utilização desse termo que percebemos a dimensão da obra: a guerra global de conteúdos e do soft power ${ }^{3}$ agora não é travada apenas pelos gigantes Estados Unidos, mas vem adquirindo contornos globais. Não que os Estados Unidos não detenham ainda o poder das indústrias do entretenimento, eles são os maiores exportadores de conteúdos do mundo e sua cultura é ainda a mais disseminada, mas o que vem acontecendo (e este é a grande contribuição da obra) é que os outros países, principalmente os emergentes, estão entrando em concorrência com eles. Por isso, o subtítulo brasileiro coube muito bem com a proposta do livro.

No que concerne à estrutura, o livro apresenta dois capítulos, divididos em 16 tópicos, dos quais os oito primeiros são dedicados exclusivamente ao estudo do entretenimento americano, denominado $O$ entertainment americano. O segundo capítulo, denominado A guerra cultural mundial, trata da geopolítica do entretenimento no resto do mundo, incluindo a conclusão: Uma nova geopolítica da cultura e da informação na era digital, em que o autor faz um balanço de toda sua pesquisa, buscando uma interpretação geral acerca dos temas tratados. Martel inicia seu percurso investigativo buscando, em primeiro lugar, entender como funciona o lobby da indústria cinematográfica dos Estados Unidos e entrevista aquele que é considerado o maior lobista de Hollywood - Jack Valenti (19212007). Passando pela força e influência da Motion Picture Association of America (MPAA), não só nos Estados Unidos mas também na América Latina, conta sobre o fracasso da instituição quanto à luta contra a pirataria e, por fim, como

3 O conceito de soft power, em oposição ao hard power (poder exercido pela coerção, por meio dos exércitos, da economia, da indústria, da censura etc.), demonstra que as nações, à maneira norte-americana, buscam exercer domínio mediante a atração pela imagens, pelas ideias, pelas culturas, pela disseminação de valores. Um conceito que realmente consegue resumir o atual estado dessa guerra global, ou seja, a busca pela dominação através do soft power. ela, se ocupando demais com esse combate, se esqueceu de seu maior objetivo: a luta contra as cotas nacionais. No entanto, Martel descobriu que atualmente o objetivo não se está mais centrado na luta contra as cotas em escala global, mas, sim, em promover parcerias em cada país, ou seja, buscando acordos em cada caso, com uma política de "multiparcerias". Por isso, possui escritórios no Brasil e no México, entre outros países.

Ao passar pelo lobby, o autor se concentra no modo de funcionamento dos drive-ins, dos shopping malls, dos exurbs e dos multiplexes, pois nesses lugares é que o cinema americano encontra sua fonte de lucro. O público americano é o maior consumidor de filmes nas salas de cinema dos grandes subúrbios. Cerca de 1,4 bilhão de entradas para o cinema são vendidas por ano, e os americanos gastam mais de 10 bilhões de dólares com isso ${ }^{4}$. Um número exorbitante, que não deixa de impressionar, principalmente quando nos defrontamos com os números de multiplexes existentes no país: cerca de 6.300 salas, com 40.000 telas repartidas. O fenômeno do multiplex se espalha também nos países emergentes, tanto é que na China e no México inaugura-se uma nova sala de multiplex por dia. No Egito, na Índia e no Brasil, os números também são altos. A relação entre o multiplex, a pipoca e a Coca-cola também é abordada na obra, além da guerra entre a Pepsi e a Coca-cola pelo público jovem, maior frequentador das salas de cinema.

Finalmente, um tópico destinado ao gigante Disney (o legado e demissão de Michael Eisner, a polêmica que envolveu o produtor Jeffrey Katzenberg) e depois as referências aos dispositivos que compõem o mainstream: o funcionamento dos grandes estúdios hollywoodianos, os sindicatos de roteiristas, diretores e atores, os setores de produção denominados "independentes", que trabalham em parceria com os grandes estúdios, e "as unidades especializadas" (espécie de subestúdio independente, pertencente aos estúdios, que privilegia produções a públicos especializados). Inclui também as agências de talentos, o marketing desenvolvido, as campanhas comerciais (extremamente dispendiosas), a invenção da pop music, o nascimento e desenvolvimento da MTV, o simbolismo do hip e do cool, e os novos juízes do gosto, agora formados por jovens de 16 anos. Ainda, a influência exercida por três mulheres midiáticas (Pauline Kael, Tina Brown e Oprah Winfrey) no que diz respeito à

\footnotetext{
4 Todos os números explicitados nesta resenha são referentes aos números que constam no livro, o qual foi escrito com base nos dados de 2008, 2009 e 2010. A primeira publicação, em língua francesa, foi em 2010.
} 


\section{Emergência de uma nova cartografia global das mídias e das culturas}

revolução dos Estados Unidos entre elite, arte e entretenimento. Trata, por fim, do papel que as universidades americanas desempenham no sucesso da indústria do entretenimento, não só para os americanos mas para pessoas de outras nacionalidades.

Os Estados Unidos não são apenas um país, nem mesmo um continente: são o mundo, ou pelo menos o mundo em miniatura. Nenhum país tem tamanha diversidade e nenhum - nem mesmo a Europa dos 27 - pode de tal maneira arvorar-se a representar uma nação universal. Esse dado é decisivo na explicação do crescente domínio das indústrias criativas americanas no mundo, arte e entretenimento, mainstream e nichos ao mesmo tempo (MARTEL, 2012, p. 209).

A segunda parte da obra adentra agora as indústrias e os meios de comunicação de países emergentes e do continente europeu. Aliás, essa segunda parte pode ser considerada a mais interessante e importante, porque é fruto de uma pesquisa relativamente nova. Além do mais, como se sabe, o estudo dos meios midiáticos americanos ou ocidentais é muito mais recorrente do que o estudo dessas mesmas indústrias em locais como China, Índia e Oriente Médio.

Martel inicia sua nova longa jornada pesquisando a respeito das indústrias de comunicação chinesas, das estratégias para imposição de uma censura oficial para se proteger do entretenimento estrangeiro, das cotas ao comércio internacional e da displicência chinesa em relação à pirataria. A obra centra o fracasso das indústrias de entretenimento americanas que vêm tentando entrar no mercado de mais um bilhão de chineses. $O$ caso do magnata Rupert Murdoch foi o mais significativo, pois demonstrou que, apesar de todo o capital e influência que possuía, não conseguiu obter o sucesso desejado no mercado chinês, atravessando diversos percalços. Aliás, como o próprio Murdoch declarara, nenhum dos grupos estrangeiros de mídia conseguiram ter algum impacto no país.

Assim, com toda essa série de dificuldades enfrentadas pelas indústrias estrangeiras na China, um novo mercado vizinho emergente desponta, sendo similarmente muito amplo: a Índia. Entretanto, esta, diferentemente daquela, possui Bollywood, que é a maior indústria de cinema indiana, fonte de sucesso, lucro e popularidade no país. Dentro desse contexto, Hollywood busca com seus blockbusters dominar o mercado indiano. Em contrapartida, Bollywood tenta competir com Hollywood, comprando produtoras nos Estados Unidos, produzindo seus próprios blockbusters e se tornar mainstream no resto mundo, o que ainda parece estar longe de acontecer, dado o poderio de Hollywood.
Nos países da Ásia como Taiwan, Japão, Coreia do Sul e Indonésia, o pesquisador francês parte em busca do entendimento acerca dos fluxos culturais existentes no continente, principalmente no que se refere aos conteúdos de música pop e os dramas (como são chamadas as telenovelas) muito difundidos naqueles países. No entanto, o fato é que o autor se defronta com outro ambiente, ainda mais complexo, em que uma batalha literalmente se trava na questão da concorrência por formatos audiovisuais e na busca de tornar os produtos culturais mainstream. Além disso, percebe que a força americana nesses países já não é mais tão grande, como fora há tempos atrás.

Para entender a geopolítica dos dramas televisivos, o autor percorre a Televisa no México, a rede Globo no Brasil, a MediaCity no Cairo, a RCTV em Caracas, entre outros. Um tópico ainda é dedicado à cultura pop latina, que tem como centro, não uma cidade própria da América Latina, mas Miami.

Voltando-se novamente para a Ásia, agora no Oriente Médio, especificamente em Catar, Martel procura entender Como a Al Jazeera se tornou a rede mainstream do mundo árabe (este é o subtítulo do 14ํㅡópico). Logo depois, ainda no Oriente Médio (na cidade de Riad, capital da Arábia Saudita), o foco recai na Rotana, rede pertencente ao príncipe Al Walled. A Rotana é um dos mais importantes grupos árabes, que também vem investindo muito capital na busca de se tornar dominante, não apenas no território árabe mas também em todo o mundo. Para Martel, é muito difícil dizer se a Rotana, como também a AMC ou a MBC, alcançará êxito em sua estratégia comercial cultural e de mídia nestes tempos de globalização. Até porque, mesmo com todo capital que esses grupos detêm, a questão dos valores árabes e a censura são a maior barreira que eles teriam de enfrentar, sem falar da concorrência dos gigantes Estados Unidos.

Contudo, para finalizar sua trajetória, o pesquisador necessitava percorrer a Europa, já que há algum tempo fora considerada o berço da arte e da cultura mainstream (principalmente a França). Pois é realmente nesse ponto que a Europa dos anos 1927 perpassa por mutações. Mesmo sendo o segundo maior exportador de conteúdos no mundo, o continente europeu troca produtos e informações entre si e não necessariamente com o resto do mundo. Além disso, ser a França uma das maiores produtoras de videogames, estando os gigantes dessa indústria (Activision, Ubisoft e Blizzard) em solo francês, não significa que vá produzir conteúdos com identidade francesa. O mesmo acontece com a Columbia, que pertence à Sony, que é japonesa: a Columbia produz filmes correspondentes ao estilo 


\section{Emergência de uma nova cartografia global das mídias e das culturas}

americano, não ao japonês. Por isso, diferentemente dos anos 1950 e das leituras neomarxistas, em que se acreditava que quem detivesse os meios de produção também controlaria os conteúdos produzidos, hoje, a realidade se mostra bem diferente. A lógica das grandes indústrias se subverteu e se descentralizou. Portanto, o que acontece com a Europa também é algo antes inimaginável: apesar de exportar conteúdos, não os exporta para os outros continentes, ou seja, seus fluxos culturais internacionais estão em declínio, o que faz com que sua cultura já não seja tão difundida para o resto do mundo.

É dentro desse novo e complexo panorama que se pode resumir a atual guerra que as mídias e culturas travam, na qual todos estão em busca de soft power. A obra de Martel busca atentar para essa nova realidade, que não estava até então muita clara até mesmo para nós que voltamos os nossos estudos para as questões da cultura da mídia. Esta obra se coloca, assim, como um projeto inovador e ao mesmo tempo ambicioso, por causa da visão holística do pesquisador, que buscou não apenas casos isolados, não se contentando somente com a afirmação de que os Estados Unidos são e sempre serão a cultura dominante. Outros países também entram no jogo, querendo competir com os americanos; embora ainda estejam longe de fazer frente à cultura americana dominante, representam o início de uma nova cartografia global das mídias e das culturas que emergem. 